\title{
Quality of Life of Patients with Vitiligo
}

\author{
Sohier Mohammed Weheda ${ }^{1}$, Heba Elsayed Khatab ${ }^{2}$, \& Hend Abdelmonem Eid Elshnawie ${ }^{3}$ \\ ${ }^{1 .}$ Professor. Medical-Surgical Nursing Department, Faculty of Nursing, Alexandria University, Egypt. \\ ${ }^{2 .}$ Lecturer, Medical-Surgical Nursing Department, Faculty of Nursing, Alexandria University, Egypt. \\ ${ }^{3 .}$ Lecturer, Medical-Surgical Nursing Department, Faculty of Nursing, Alexandria University, Egypt.
}

\begin{abstract}
Vitiligo has more than a 3000year history, it affected quality of life and led to greater stigmatization of affected patients. Nowadays, in a more holistic view of management a decisive factor to understand the impact of diseases and improve the quality of nursing care. Researchers must be aware of how some diseases affect different aspects of patients' lives and how successful management may improve patients' quality of life Aim: Assess quality of life of patient with vitiligo Material \& Methods: Design A descriptive design was used. Setting: Mina Elbasel dermatology hospital. Alexandria, Egypt. Subjects: A convenience sample of 100 patients Tools for data collection: Two tools were used for data collections Tool1: of patient with vitiligo assessment questionnaire, to determine sociodemographic characteristic, and clinical data, Tool 2: vitiligo life quality interview questionnaire to assess the quality of life in patient with vitiligo. Results: Majority of the studied patient sometimes had difficulty with sun exposure, had challenges at their school or work, felt uncomfortable when asked questions about their disease, felt embarrassment from vitiligo, issues with their partner, avoided physical contact with others or shared them, and they had family issues, felt isolated and had problems in their sexual relations. Also, there were a statistically significant correlation between quality of life for patients under study and their vitiligo in relation to their sex, occupation, level of education and marital status, disease duration and their family history. Conclusions: Quality of life should be considered as one of the important outcome measures of management in patients with vitiligo. Recommendations: Nurses should develop strategies to provide an effective educational program for patients with vitiligo 'to enhance their quality of life
\end{abstract}

\section{Keywords: Quality of life, Vitiligo \& Millanin .}

\section{Introduction}

Melanin is the necessary pigmentation for skin color. Vitiligo is an acquired multi-factorial idiopathic pigmentary change of the skin, where partial or complete loss of melanocytes from patches of skin produces irregular white spots Dhvani, et al (2014). It is characterized by depigmented patches, wellcircumscribed ivory or, chalky white macules which are flush to the skin surface and affect 1-2\% of population Hedayat, et al (2016). Although it is not life threatening, it affects one's appearance causing chronic cosmetic problems Şenol, et al (2013). The incidence of vitiligo in India, Egypt, and Japan is higher. It ranges from $1.25 \%$ to $6 \%$ of the population Dhvani et al (2014).

Vitiligo patches contain either reduced melanin or no pigment at all. Initially it starts small patches, then they may enlarge into larger patches. It presents on the face, back of hands, wrists, and the axilla or umbilicus are especially prominent. Vitiligo is most striking around the body orifices: eyes, nostrils, mouth, nipples, umbilicus, and genitalia Hamat et al., (2014).

The cause of vitiligo is unknown, but there are many theories for its pathogenesis including bio-chemical cytotoxic theory, neural and autoimmune theory, viral theory, and intrinsic theory. The first one is the biochemical/cytotoxic hypothesis described that vitiligo occurs when the melanocyte is killed by cytotoxic precursors to melanin synthesis. The second one the neural theory is based on nerve injury development with affected sites that leads to segmental vitiligo with neurons that interact with melanocytes and release melano-cytotoxic substrates. The autoimmune theory is based on genetic data which are more associated with autoimmune diseases. Hamat et al., (2014) \&Mohamed et al., (2015)

The viral theory based on a strong association between vitiligo and chronic hepatitis $\mathrm{C}$ virus (HCV) infection and autoimmune hepatitis; certain studies reported a low hepatitis B virus (HBV) seropositivity in vitiliginous patients. Previous or concurrent cytomegalovirus (CMV) infections may induce the etiopathogenesis or deterioration of vitiligo. Furthermore, other viruses as Epstein-Barr virus, hepatitis E virus, herpes virus, and the human immunodeficiency virus (HIV) also have a suspicious association with vitiligo. The intrinsic theory is based on abnormal rough endoplasmic reticulum or deficiency of unidentified melanocyte growth factors such as basic fibroblast growth factor (bFGF) and 
decrease in the number of melanocytes expressing the c-kit receptor in skin lesion. In addition to convergence theory, which described that stress, results in accumulation of toxic compounds, infection, autoimmunity, mutations, altered cellular environment, and impaired melanocyte migration and proliferation can all contribute to the pathogenesis of vitiligo, Hamat et al.,(2014), David, Isedeh, Iltefat (2014) Mohamed et al., (2015), \& Arora, Kumaran (2017).

The skin is the biggest and most observable organ of the human body. Subsequently, any disturbance on the skin influences the person, and along these lines, the individual is influenced significantly, Hammam, et al., (2019). vitiligo is an important skin disease having a major impact on the quality of life of patients, which defined as a multi-dimensional index of different social, behavioral, and cultural factors, Parsad (2003), Mishra, Marjan (2008),\& Rastogi, Gahalaut(2014).

WHO defines QOL as 'individuals' perceptions of their position in life in the context of the culture and value systems in which they live and their goals, expectations, standards and concerns" (WHO 2012)

Quality of nursing care is the degree to which health care for the patient increases the probability of the desired outcome and consistent with current professional knowledge (Mains, \& Andaleeb, 2016). QOL is affected by an individual's physical and mental health, the degree of independence, the social relationship with the environment, and other factors. The goal of much care in chronic illness is to improve QOL. As regards the assessment of the quality of life the nurse can use distinct methods that measure health status aspects as physical functioning, role limitations due to physical health, role limitations due to emotional problems, energy/fatigue, psychological well-being, social functioning, pain assessment, and general health. These aspects can be used as notices to measure any improvement or deterioration in health status (WHO 2012).

\section{Significance:}

Although vitiligo is not life threaten conditions It is present worldwide, as prevalence in different countries ranges from less than $0.1 \%$ to more than $8 \%$ of the general population $(1 \%$ in the United States and in Europe) ; thus, it can be estimated that approximately 100 million people in the world are affected. While as reports suggest that incidence of vitiligo in India, Egypt, and Japan is higher. Which ranges from $1.25 \%$ to $6 \%$ of the total population although these data, worldwide the awareness, and knowledge of vitiligo are often inadequate. and there are several misconceptions in the correct approach to this disease. Moreover, vitiligo often develops a negative significant impact on the social and psychological and physical domains of the patients' life. Also, some studies report feeling of embarrassment among the patients, which can lead to low self-esteem, social isolation, stigmatization, depression, and self-consciousness. As results it could lead to poor medical care, disorder in personal behavior, diet, pollution, and they have doubts or wrong ideas about contagiousness, and noncompliance toward their therapeutic regimen. On the other hand, patients with vitiligo are at risk of higher social, and occupational discrimination. So, the nurses play an important role in assessing, plan and implement suitable care for each patient with vitiligo. In the future, more research is needed to evaluate standardized rating tools that can help nurses to assess the personal impact that vitiligo may have on a patient's life Marjan et al., (2008), Lilly, et al., (2013), \& David, et al., (2014).

The purpose of this study is to assess the quality of life of patients with vitiligo.

\section{Research question}

What is the quality of life of patients with vitiligo?

\section{Subjects and method \\ Research design}

A descriptive design was used to conduct this study. Setting:

The study was conducted at the Mina Elbasel dermatology Hospital. Alexandria, Egypt.

\section{Subject:}

The study included a convenience sample of 100 adult patients and not above 60 years old, admitted to the dermatology outpatient clinics complained of vitiligo and without other skin diseases (as burn, erythema, cancer skin)

\section{Sample size}

Epi info program v 7.0 was used to find the sample size by applying the following parameters:

Expected frequency $50 \%$

Acceptable error 5\%

Confidence coefficient $95 \%$

Population size 200 patients in three months

So minimum sample size 100 patients

\section{Tools:}

Two tools were used in this study which includes: Tool I: Patient with vitiligo assessment questionnaire:

This tool was developed by the researcher after review of the relevant literature, Weber Lorenzini , Reinehr (2012) and it was used to assess Patient's socio-demographic data and clinical data. it based on two parts 


\section{Part I:}

This part includes patient's socio demographic data such as; age, sex, education, occupation, marital status and place of residence

\section{Part II:}

This part includes clinical data such as medical diagnosis, medical history as; disease duration, family history, areas involved, and prescribed current treatment/ medications.

Tool II: vitiligo life quality assessment interview questionnaire index:

This part of the tool was adopted from Şenol et al., (2013). It was made up of 25 questions to assess quality of life of patient with vitiligo. It response by a four point Likert scale (1-4). Each question of it presented as 1= "never", 2="sometimes", 3="often", and $4=$ " all the time".

\section{Scoring system:}

The vitiligo life quality is calculated by summing the score of each question resulting in a maximum of 100 and a minimum of 0 . The higher score showed poorer quality of life.

\section{The field work:}

An official letter was obtained from the administrative office of the Faculty of Nursing. A written approval was obtained from the hospital administrators after explanation of the study aim. The study tool I were developed by the researcher after a thorough review of relevant literature. Tools II was adopted and modified by the researcher.

Validity and Reliability of the study tools:

- The tools were submitted to 5 experts in Medical Surgical Nursing, to test its content validity.

- Reliability of the tool II was done by using (Cronbach's Alpha test0.92). One hundred adult patients diagnosed with vitiligo were assigned as represented sample of the study. Every patient in the group was interviewed, using the tools I, II.

\section{Pilot study:}

It was conducted on $\mathbf{1 0}$ patients for testing, clarity, feasibility and applicability of the study tools, and time needed to answer the tools. Those patients were excluded from the sample subjects before starting data collection, and then replaced it by collected 100 study patients to perform study

\section{Data collection:}

- After securing administrative approval, data collection was initiated covering a period of 8 months from April 2020 to the end of November 2020 .
- The total subjects consisted of 100 adult patients with vitiligo. All patients met the criteria of subjects' selection in the study.

- The study aim was explained to every patient by the researcher. Each patient was interviewed individually by the researcher in the outpatient clinic.

- The interview took 30 to 45 minutes to collect the needed data related to socio-demographic and assess quality of life among vitiligo patients by using the developed tool.

- Researcher collected data at 3 days (Saturday, Monday and Thursday) in each week for 2 months

\section{Ethical consideration:}

The researcher introduced herself to every patient, included in the study, and explained the purpose of the study. Patient's informed consent to participate in the study was obtained. Every patient was informed that anonymity, data confidentiality, and patient's privacy will be assured.

\section{Statistical analysis:}

The following statistical measures were used:

a. Reliability test: reliability was measured by Cronbach's Alpha test for the vitiligo life quality index was( 0.92).

b. After data collection, the raw data were coded and entered into SPSS system files (SPSS package version 20). Analysis and interpretation of data were conducted 
Results:

Table (1): Distribution of the studied patients according to their socio demographic characteristics $(\mathbf{n}=\mathbf{1 0 0})$

\begin{tabular}{|c|c|c|}
\hline Variable & $\begin{array}{c}\text { No } \\
\mathbf{n}=100 .\end{array}$ & $\%$ \\
\hline \multicolumn{3}{|l|}{ Age (years) } \\
\hline $20<30$ years & 15 & 15.0 \\
\hline $30<40$ years & 39 & 39.0 \\
\hline $40<50$ years & 32 & 32.0 \\
\hline $50 \leq 60$ years & 14 & 14.0 \\
\hline \multicolumn{3}{|l|}{ Sex } \\
\hline Male & 44 & 44.0 \\
\hline Female & 56 & 56.0 \\
\hline \multicolumn{3}{|l|}{ Occupation } \\
\hline Clerical & 40 & 40.0 \\
\hline Professional & 15 & 15.0 \\
\hline Housewife/ Non worker & 45 & 45.0 \\
\hline \multicolumn{3}{|l|}{ Level of education } \\
\hline Illiterate & 27 & 27.0 \\
\hline Read \& write & 38 & 38.0 \\
\hline Primary & 7 & 7.0 \\
\hline Secondary & 13 & 13.0 \\
\hline University & 15 & 15.0 \\
\hline \multicolumn{3}{|l|}{ Marital status } \\
\hline Single & 22 & 22.0 \\
\hline Married & 55 & 55.0 \\
\hline Divorced & 15 & 15.0 \\
\hline Widow & 8 & 8.0 \\
\hline \multicolumn{3}{|l|}{ Area of residence } \\
\hline Rural & 49 & 49.0 \\
\hline Urban & 51 & 51.0 \\
\hline
\end{tabular}

Table (2): Distribution of the studied patients according to their clinical data $(n=100)$

\begin{tabular}{|l|c|c|}
\hline \multicolumn{1}{|c|}{ Variable } & $\begin{array}{c}\text { No. } \\
\mathbf{n}=\mathbf{1 0 0}\end{array}$ & $\%$ \\
\hline Disease duration (months) & & 14 \\
\hline $1<3$ months & 31 & 31.0 \\
\hline $3<6$ months & 21 & 21.0 \\
\hline $6<12$ months & 34 & 34.0 \\
\hline 12 month \&more & & 42.0 \\
\hline Family history & 42 & 58.0 \\
\hline Yes & 58 & 59.0 \\
\hline No & & 10.0 \\
\hline Area involved & 59 & 14.0 \\
\hline Face/ hands & 10 & 16.0 \\
\hline Hands & 14 & \\
\hline Trunk & 16 & \\
\hline Genitalia & & 72.0 \\
\hline Prescribed current medications & 72 & 10.0 \\
\hline Topical medication/ Corticosteroids & 10 & 18.0 \\
\hline Corticosteroids & 18 & 0.0 \\
\hline Phototherapy & 0 & \\
\hline Others & & \\
\hline
\end{tabular}


Table (3): Effect of vitiligo of the studied patients on their quality of life

\begin{tabular}{|c|c|c|c|c|c|c|c|c|}
\hline \multirow{2}{*}{ Items } & \multicolumn{2}{|c|}{ Never } & \multicolumn{2}{|c|}{ Sometimes } & \multicolumn{2}{|c|}{ Often } & \multicolumn{2}{|c|}{ All the time } \\
\hline & No. & $\%$ & No. & $\%$ & No. & $\%$ & No. & $\%$ \\
\hline \multicolumn{9}{|l|}{ Do you have: } \\
\hline Pain, irritation, or itching due to vitiligo & 34 & 34.0 & 48 & 48.0 & 10 & 10.0 & 8 & 8.0 \\
\hline $\begin{array}{l}\text { Feeling of embarrassment or insecure due to your appearance } \\
\text { with vitiligo }\end{array}$ & 25 & 25.0 & 53 & 53.0 & 16 & 16.0 & 6 & 6.0 \\
\hline Feeling of uneasy about others staring at you because of vitiligo & 33 & 33.0 & 45 & 45.0 & 10 & 10.0 & 12 & 12.0 \\
\hline Start using make-up to conceal vitiligo? & 77 & 77.0 & 23 & 23.0 & 0 & 0.0 & 0 & 0.0 \\
\hline Start using clothing specifically to cover up vitiligo & 80 & 80.0 & 20 & 20.0 & 0 & 0.0 & 0 & 0.0 \\
\hline Low self-esteem because of vitiligo. & 13 & 13.0 & 31 & 31.0 & 43 & 43.0 & 13 & 13.0 \\
\hline Feeling not wanted others to see your body due to vitiligo & 8 & 8.0 & 15 & 15.0 & 48 & 48.0 & 29 & 29.0 \\
\hline concerning about vitiligo spreading to other parts of your body & 7 & 7.0 & 13 & 13.0 & 43 & 43.0 & 37 & 37.0 \\
\hline concerns about getting skin cancer because of vitiligo & 6 & 6.0 & 27 & 27.0 & 43 & 43.0 & 24 & 24.0 \\
\hline Anxiety as vitiligo being permanent & 7 & 7.0 & 44 & 44.0 & 32 & 32.0 & 17 & 17.0 \\
\hline worried that your children might inherit vitiligo from you & 6 & 6.0 & 41 & 41.0 & 45 & 45.0 & 8 & 8.0 \\
\hline $\begin{array}{l}\text { Uncomfortable feeling when looking in the mirror due to } \\
\text { vitiligo }\end{array}$ & 11 & 11.0 & 40 & 40.0 & 32 & 32.0 & 17 & 17.0 \\
\hline $\begin{array}{l}\text { To stayed away from crowded areas (shopping centers, public } \\
\text { transportation, etc.) due to your vitiligo }\end{array}$ & 11 & 11.0 & 29 & 29.0 & 49 & 49.0 & 11 & 11.0 \\
\hline difficulty with sun exposure or protection due to your vitiligo & 13 & 13.0 & 46 & 46.0 & 33 & 33.0 & 8 & 8.0 \\
\hline Feeling that vitiligo affected your vacation plans & 12 & 12.0 & 34 & 34.0 & 36 & 36.0 & 18 & 18.0 \\
\hline $\begin{array}{l}\text { Feeling that vitiligo had an impact on what you do on your free } \\
\text { time, your activities, and hobbies }\end{array}$ & 20 & 20.0 & 55 & 55.0 & 17 & 17.0 & 8 & 8.0 \\
\hline Any challenges at school or work due to vitiligo & 27 & 27.0 & 49 & 49.0 & 21 & 21.0 & 3 & 3.0 \\
\hline $\begin{array}{l}\text { Uncomfortable Feeling with questions asked about your vitiligo } \\
\text { and the explanations that you had to make }\end{array}$ & 10 & 10.0 & 35 & 35.0 & 29 & 29.0 & 26 & 26.0 \\
\hline Feeling of isolated or been made fun due to vitiligo & 14 & 14.0 & 51 & 51.0 & 24 & 24.0 & 11 & 11.0 \\
\hline issues with your partner due to vitiligo & 16 & 16.0 & 37 & 37.0 & 29 & 29.0 & 18 & 18.0 \\
\hline $\begin{array}{l}\text { avoided physical contact with others (shake hands, give hugs or } \\
\text { kisses, etc.) because of vitiligo }\end{array}$ & 21 & 21.0 & 35 & 35.0 & 22 & 22.0 & 22 & 22.0 \\
\hline family issues due to vitiligo & 12 & 12.0 & 34 & 34.0 & 31 & 31.0 & 23 & 23.0 \\
\hline $\begin{array}{l}\text { uneasy Feeling about sharing personal items with the household } \\
\text { due to vitiligo }\end{array}$ & 14 & 14.0 & 43 & 43.0 & 26 & 26.0 & 17 & 17.0 \\
\hline $\begin{array}{l}\text { Difficulty keeping up with vitiligo therapy (spending too much } \\
\text { time or money, applying medicine, etc.) }\end{array}$ & 18 & 18.0 & 42 & 42.0 & 24 & 24.0 & 16 & 16.0 \\
\hline problems in your sexual relations because of vitiligo & 16 & 16.0 & 59 & 59.0 & 24 & 24.0 & 8 & 8.0 \\
\hline
\end{tabular}

Table (4): Total quality of life percent scores for studied patient with vitiligo $(n=100)$

\begin{tabular}{|c|c|c|}
\hline \multicolumn{1}{|c|}{ Variable } & Total Score & \% Score \\
\hline Vitiligo quality of life & & \\
\hline Min. - Max. & $44.0-66.0$ & $25.33-54.67$ \\
\hline Mean \pm SD. & $58.49 \pm 5.23$ & $44.65 \pm 6.98$ \\
\hline
\end{tabular}

Table (5): Relation between the sociodemographic characteristics and Total score quality of life of the studied patients with vitiligo

\begin{tabular}{|c|c|c|}
\hline Variable & $\begin{array}{l}\text { Total score } \\
\text { Mean } \pm \text { SD. }\end{array}$ & Statistical test\& $P$ value \\
\hline Age & & \multirow{5}{*}{$\begin{array}{l}F=5.025 \\
P=\mathbf{0 . 0 0 3}\end{array}$} \\
\hline $20-$ & $54.00 \pm 7.061$ & \\
\hline $30-$ & $59.69 \pm 4.996$ & \\
\hline $40-$ & $58.91 \pm 3.888$ & \\
\hline $50-60$ & $59.00 \pm 4.188$ & \\
\hline \multicolumn{2}{|l|}{ Sex } & \multirow[b]{2}{*}{$\mathrm{T}=8.136$} \\
\hline male & $56.86 \pm 5.913$ & \\
\hline
\end{tabular}




\begin{tabular}{|c|c|c|}
\hline Variable & $\begin{array}{l}\text { Total score } \\
\text { Mean } \pm \text { SD. }\end{array}$ & Statistical test\& $P$ value \\
\hline female & $59.77 \pm 4.264$ & $P=0.005 *$ \\
\hline Occupation & & \multirow{4}{*}{$\begin{array}{c}\mathrm{F}=6.242 \\
\mathbf{P}=\mathbf{0 . 0 0 0} *\end{array}$} \\
\hline clerical & $61.63 \pm 3.335$ & \\
\hline professional & $60.00 \pm 4.766$ & \\
\hline Housewife/not working & $59.46 \pm 4.111$ & \\
\hline Level of education & & \multirow{6}{*}{$\begin{array}{c}F=3.861 \\
\mathbf{P}=\mathbf{0 . 0 0 6}^{*}\end{array}$} \\
\hline illiterate & $56.81 \pm 4.532$ & \\
\hline Read \& write & $57.32 \pm 5.710$ & \\
\hline Basic & $59.57 \pm 4.685$ & \\
\hline secondary & $61.23 \pm 4.226$ & \\
\hline university & $61.60 \pm 4.188$ & \\
\hline Marital status & & \multirow{5}{*}{$\begin{array}{c}\mathrm{F}=3.332 \\
\mathbf{P}=\mathbf{0 . 0 2 3} *\end{array}$} \\
\hline Single & $57.09 \pm 7.565$ & \\
\hline Married & $58.36 \pm 4.240$ & \\
\hline Divorced & $58.27 \pm 4.044$ & \\
\hline Widowed & $63.63 \pm 2.774$ & \\
\hline Area of residence & & \multirow{3}{*}{$\begin{array}{l}T=0.366 \\
\mathbf{P}=\mathbf{0 . 5 4 7}\end{array}$} \\
\hline Rural & $58.49 \pm 6.332$ & \\
\hline Urban & $58.49 \pm 3.967$ & \\
\hline
\end{tabular}

Table (6): Relation between the clinical characteristics and total score of quality of life among the studied patient with vitiligo

\begin{tabular}{|c|c|c|}
\hline Variable & $\begin{array}{c}\text { Total score } \\
\text { Mean } \pm \text { SD. }\end{array}$ & Statistical test\& $P$ value \\
\hline Disease duration & & \\
\hline$<3$ months & $52.93 \pm 6.220$ & \multirow{4}{*}{$\begin{array}{l}F=15.675 \\
P=0.000 *\end{array}$} \\
\hline $3-$ & $56.61 \pm 4.602$ & \\
\hline $6-$ & $61.57 \pm 2.399$ & \\
\hline $12+$ & $60.59 \pm 4.142$ & \\
\hline family history & & \multirow{3}{*}{$\begin{array}{c}\mathrm{T}=3.789 \\
\mathbf{P}=\mathbf{0 . 0 5 4}\end{array}$} \\
\hline Yes & $57.31 \pm 6.119$ & \\
\hline No & $59.34 \pm 4.343$ & \\
\hline Area .involved & & \multirow{3}{*}{$\begin{array}{l}T=3.480 \\
\mathbf{P}=\mathbf{0 . 0 6 8}\end{array}$} \\
\hline External & $55.76 \pm 6.262$ & \\
\hline Internal & $58.88 \pm 3.243$ & \\
\hline
\end{tabular}

Table1: Shows number and percentage distribution of socio-demographic characteristics among studied patients with vitiligo. It was noticed that more than half of studied patients their age between 30 to less than50 years old. And about $(56 \%)$ of them are female. Concerning occupation, the results showed that less than half $(45 \%)$ of studied patient were housewife, or not worker while (15\%) of them have a professional work. Regards the level of education the results revealed that about $38 \%$ of studied patients were read and write while less than quarter of them $(15 \%)$ had university education. Finally, the results noticed that the Majority of the studied patient (55\%) were married and live-in rural area

Table2: Illustrates distribution of studied patients according to their clinical data . it was founded that less than half of studied patients have disease from 12 months or more while as $14 \%$ of them have vitiligo from 1 to 3 months. on the other hand, about $58 \%$ of studied patient have no family history of developing vitiligo. As regards vitiligo affected area the result showed that more than half of studied patient have vitiligo in their face and hand while $14 \%$ of them affected in their trunk. Finally, the results noticed that more than two third of studied patient $(72 \%)$ were treated by tropical medications \& corticosteroid.

Table 3 : Shows effect of vitiligo on patients quality of life, Less than half of studied patient sometimes had pain, irritation, or itching due to vitiligo, felt embarrassed and felt uneasy about others staring at them because of vitiligo $(48 \%, 45 \%)$ respectively. On the other hand, the results noticed that the majority of studied patient never used makeup to conceal vitiligo or pick out clothing to cover vitiligo. While as nearly 
half of studied patient often had low self-esteem, and they don't wanted others to see their body, Moreover, about $43 \%$ of total studied patients often had concern about vitiligo spreading to other parts of their body, getting skin cancer, and also, the results illustrated that more than quarter of studied patients often worried about their children to inherit vitiligo from them, stayed away from crowded area and vitiligo effect on their vacation plan $(45 \%, 49 \% .36 \%)$ respectively.

On the other hand, the majority of the studied patient sometimes had difficulty with sun exposure, had challenges at their school or work, felt uncomfortable with questions asked about their vitiligo, $(46 \%, 49 \%, 36 \%)$ respectively. Also nearly half of studied patient had sometimes issues with their partner, avoided physical contact with others or shared personal items, and they had family issues $(37 \%, 35 \%, 43 \% 34 \%$,). Also, more than half of studied patient $(59 \%)$ sometimes had problems in their sexual relations.

Table (4): Shows Total quality of life percent scores for studied patient with vitiligo were $44.65 \pm 6.98$ with total score $58.49 \pm 5.23$.

Table (5): Illustrates that there are a relation between studied patients with vitiligo sociodemographic characteristics and their total score of quality of life. Also, there were a relation between socio demographic characteristics and quality of life of studied patients with vitiligo in relation to their sex, occupation, level of education and their marital status with $(\mathrm{p}=0.005, \mathrm{p}=0.000, \mathrm{p}=0.000, \mathrm{p} .0023)$ respectively

Table (6): Illustrated a relation between the clinical characteristics and Total score of quality of life of studied patient with vitiligo. Also, there were significant relation between clinical characteristics and quality of life of studied patients with vitiligo related to their disease duration and their family history with $(\mathrm{p}=0.000, \mathrm{p}=0.068)$ respectively

\section{Discussion}

Vitiligo is one of the most important skin disorders that does not cause direct impairment in patient general condition, but due to its disfiguring appearance, patients have disturbances in their health and quality of life (QoL). Although the disease does not produce direct physical impairment, It has been found that patients has low self-esteem, poor body image, and poor physical impairment, which had a direct effect on their quality of life so the aim of the study to identify the quality of life in patient with vitiligo.

As regards sociodemographic status the present study found that about half of studied patients their age between 30 to less than50 years old this result were similar as by. Sehgal \& Srivastava (2007), who reported which stated that vitiligo occurs in age of 30 years old in contrast Lee et al., (2015) who founded that nearly $70-80 \%$ of vitiligo patients age were before 20 years old. Also, they stated that vitiligo were the most commonly appears in people ages 10 to 30 years old. Vitiligo rarely appears in the very young or very old. On the other hand the results reveled that the majority of studied patient who have a vitiligo were female, unlike the Hammam, et al., (2019), who did not find that there were no any gender difference in the incidence of the disease while as Sangma, et al., (2015). found that most vitiligo patients were female. Regards family history, the results revealed that, more than half of studied patients have not family history of vitiligo these results were in agreement with Neena, et al (2019), \& Vachiramon, et al (2020) results who explained that there were a several combination of factors responsible about vitiligo.as genetic factors, exposures for physical or emotional stress, or Neurogenic factors which was a result of substance that is toxic to melanocytes which may be released at nerve endings in the skin. which lead to defect in the melanocytes causes them to destroy themselves also, Gardner (2019) believe that autoimmunity plays a role in vitiligo. That's when immune system mistakenly attacks any part of body. And destroy the melanocytes in the skin. like some autoimmune disease Hashimoto's diseases are more likely to get vitiligo. In contrast Mishra et al., ( 2014) results noticed that about $30 \%-40 \%$ vitiligo frequently occurred in patients and their family members and Vachiramon et al., (2020). added Approximately $20 \%$ of the patients with vitiligo have at least one close blood relative with the disease.

On the other hand, the findings of this study noticed that more than half of studied patient have vitiligo in their face and hand as similar with JOHN \& Harris (2020) findings who stated that over $80 \%$ of those with vitiligo most frequently affects the face and/or hands. Also Gardner (2019) explained that vitiligo mainly affects the face in the area of innervation of the trigeminal nerve, following this in terms of frequency, the thoracic, cervical, lumbar and sacral innervated areas. Thus, it is common to observe poliosis of eyelashes and hair in this form of the disease. But Karelson, et al., (2009) \& Vachiramon, et al., (2020). Have reported upper limbs as most common site of vitiligo. Nevertheless, we believe that exposed area and trauma-prone sites, such as the lower limbs and hands, may develop vitiligo lesions more easily in genetically risk individuals. 
As regards the effect of quality of life with vitiligo the findings of this study showed that the majority of the studied patient sometimes had difficulty with sun exposure, challenges at their school or work, felt uncomforted when asked about their vitiligo, felt embarrassed from vitiligo, sometimes issues with their partner, avoided physical contact with others or shared personal items, and they had family issues as they felt isolated and had problems in their sexual relations, these agree with Raheel, et al., (2019) who explained that the patient with vitiligo had poor quality of life due to Appearance of their skin condition, self-image, and pathological alteration can have psychological and physiological consequences on their management and life. Many vitiligo patients feel distressed and stigmatized by their condition. So, these patients sometimes develop negative feeling about their daily living activities as working, sports partner relationship and socialization which are reinforced by their experiences over a number of years. Most patients of vitiligo reported feelings of embarrassment, which can lead to a low self-esteem and social isolation. These finding contradicting with Takemasa, et al., (2014), \& Gardner (2019) in their studies, as they who reported that patients with vitiligo usually avoid sport or restrict such activities, so they may lose vital days from school, or work, in our opinion patients with vitiligo deal with the disease well or frustration which these often depending on their family attitude, siblings, relatives, teachers, friends which had a great effect on their prognosis of management and outcomes

Finally the findings of this study revealed that there were positive significant relation between socio demographic characteristics of studied patients with vitiligo and their quality of life as regarded to their sex, occupation, level of education and their marital status as similar with Kanwar et al., (2014), \& Neena, et al., (2019 ) who stated that there were significant correlation between marital status and vitiligo quality of life as they found that single patients with vitiligo had a significantly higher impairment of quality of life than married ones. Also, patient with low educated have not information about the disease which may lead to feeling by frustration, depression and low outcome regarding management of the diseases', Furthermore, there were a significant association between clinical characteristics of the studied patients with vitiligo and their quality of life in relation to their disease duration and their family history, this are similar with Ezzedine, et al., (2015), \& Gardner (2019), who reported that there were a significant correlation between the duration of disease and patients quality of life. They explained that long duration of the disease could probably be attributed to its slow progression and poor disease outcome. Also, there were significant positive correlation between family history of disease and quality of life this results agreed by Boza, et al., (2015), \& Neena et al., (2019), who explained that the family history encourage patients to become worry about their children as they might inherited vitiligo too. In contrast Gardner (2019) stated that there were no correlation between vitiligo quality of life and family history as the result of this study suggested that vitiligo were impair the quality of life in all aspect of life so the nurse should put all aspect of physical, social and psychological conditions of patient in her plan of care patient with vitiligo to improve their progress of disease and life as well.

\section{Conclusion:}

So the study finding conclusion revealed that vitiligo affects physically, socially, and psychologically life of the patients, which may lead to poor outcomes. Moreover, there were association between clinical characteristics and quality of life of the studied patients with vitiligo in relation to their disease duration and their family history

\section{Recommendations:}

It was recommended that develop an educational program for a patient with vitiligo based on their needs will improve their quality of life.

\section{References:}

- Arora K, Kumaran M. (2017): Pathogenesis of vitiligo: An update. Pigment international; 4(2):65-77.

- Boza JC, Kundu RV, \& Fabbrin A. (2015): Translation, cross-cultural adaptation, and validation of the vitiligo-specific health-related quality of life instrument (VitiQoL) into Brazilian Portuguese. A Bras Dermatol; 90:358-362.

- David C; Isedeh P, \& Iltefat H. (2014): Vitiligo: a review of the pathogenesis. Journal of the Egyptian Women's Dermatologic Society ; 11 ( 3 ): $145-58$

- Dhvani M. Lakhani, \& Ashwini S. (2014): Various Treatments for Vitiligo: Problems Associated and Solutions.Journal of Applied Pharmaceutical Science ; 4 (11: 101-5.

- Ezzedine K, Grimes PE, \& Meurant JM. (2015): Living with vitiligo: results from a national survey indicate differences between skin phototypes. Br J Dermatol; 173:607-609. 
- Gardner A. A (2019): https://www.health.com/condition/vitiligo/vitiligo -causes.

- Hamat R. (2014): Vitiligo: Symptoms, Pathogenesis and Treatment. International journal of immunopathology and pharmacology; 27(4): 485-48.

- Hammam M, Yasien H, \& Algharably A. ( 2019): Effect of Vitiligo Area Scoring Index on the quality of life in patients with vitiligo.Menoufia medical journal,32(1):244-9

- Hedayat K, Karbakhsh M, \& Ghiasi M. (2016): Quality of life in patients with vitiligo: a cross-sectional study based on Vitiligo Quality of Life index (VitiQoL). Health Quality Life Outcomes.Journal; 14: 86.

- John E. Harris. (2020): Pattern of vitiligo. https://www.umassmed.edu/vitiligo/blog/blogposts1/2020/05/patterns-of-vitiligo.

- Kanwar AJ, Mahajan R, \& Parsad D. (2014): Type 2A Koebner phenomenon in vitiligo is distinct from other subtypes: observations from an Indian cohort. Br J Dermatol; 170:586-590.

- Karelson M, Silm H, \& Kingo K. (2013): Quality of life and emotional state in vitiligo in an Estonian sample: comparison with psoriasis and healthy controls. Acta Derm Venereol; 93:446450.

- Lee H, Lee MH, Lee DY, Kang HY, Kim KH, \& Choi GS, (2015): Prevalence of vitiligo and associated comorbidities in Korea. Yonsei Med J.; 56(3):719-25.

- Lilly E, Lu PD, \& Borovicka JH. (2013): Development and validation of a vitiligo-specific quality-of-life instrument (VitiQoL). J Am Acad Dermatol;69: e11-e18.

- Mains, F.H \& Andaleeb, S.S. (2016): Service quality perceptions and client satisfaction: A study of hospitals in a developing country (4th ed ). Pp. 1359-1370.

- Marjan D, Payam G, Vida F, \& Rezaei H. (2008): Life quality assessment among patients with vitiligo: Comparison of married and single patients in Iran. Indian Journal of Dermatology, Venereology and Leprology; $\mathrm{Vol}(74), \mathrm{No}(6)$.

- Mishra N., Rastogi M, \& Gahalaut P. (2014): Dermatology Specific Quality of Life in Vitiligo Patients and Its Relationship with Various Variables: A Hospital Based Cross-sectional Study.Journal of Clinical and Diagnostic Research; Vol (8), No (6).

- Mohammed G, Gomaa A, Al-Dhubaibi M. (2015): Highlights in pathogenesis of
vitiligo.World Journal Clinical Cases; 16 (3): 221-30.

- Neena S. Sawant, \& Nakul A. (2019): Gender Differences in Depression, Coping, Stigma, and Quality of Life in Patients of Vitiligo, Dermatology Research and Practice ,Vol(10),No(11)Pp: 1-10.

- Raheel Zubair, Iltefat H. Hamzavi. (2019): Phototherapy for Vitiligo, Dermatologic Clinics, 10.1016/j.det.08.005.

- Ramien ML, Ondrejchak S, Gendron R, Hatami A, McCuaig CC, Powell J, \& Marcoux D. (2014): Quality of life in pediatric patients before and after cosmetic camouflage of visible skin conditions. J Am Acad Dermatol; 71:935940.

- Sangma LN, Nath J, \& Bhagabati D. (2015): Quality of life and psychological morbidity in vitiligo patients: a study in a teaching hospital from north-East India. Indian J Dermatol; 60:142146

- Sehgal VN, |\& Srivastava G. (2007): Vitiligo: compendium of clinico-epidemiological features. Indian J Dermatol Venereol Leprol. May-; 73(3):149-56.

- Şenol A, Yücelten A, \& Ay P. (2013): Development of a Quality of Life Scale for Vitiligo. Journal of dermatology

- Takemasa S, Nakagoshi R, \& Murakami M. (2014): Factors affecting quality of life of the homebound elderly hemiparetic stroke patients. J PhysTher Sci. 26(2):301-3. doi: 10.1589/jpts.26. PubMed PMID: 24648653; PubMed Central PMCID: PMC3944310

- Vachiramon V, Onprasert W, \& Harnchoowong S. (2020): Prevalence and Clinical Characteristics of Itch in Vitiligo and Its Clinical Significance. Biomed Res Int.

- Van Geel N, Speeckaert M, Brochez L, Lambert J, \& Speeckaert R. (2014): Clinical profile of generalized vitiligo patients with associated autoimmune/autoinflammatory diseases. J Eur Acad Dermatol Venereol; 28:741746.

- Weber MB, Lorenzini D, \& Reinehr. (2012): Assessment of the quality of life of pediatric patients at a center of excellence in dermatology in southern Brazil. An Bras Dermatol; 87:697702.

- World Health Organization (2012): Division of mental health and prevention of substance abuse 